\title{
Bulk Ultrafine-Grained Interstitial-Free Steel Processed by Equal-Channel Angular Pressing Followed by Flash Annealing
}

\author{
Deepa Verma, Shobhit A. Pandey, Anushka Bansal, Shwetank Upadhyay, N.K. Mukhopadhyay, G.V.S. Sastry, and R. Manna
}

\author{
(Submitted March 19, 2016; in revised form September 7, 2016; published online October 24, 2016)
}

\begin{abstract}
Interstitial-free steel workpieces are deformed by equal-channel angular pressing (ECAP) for equivalent strain $\varepsilon_{\mathrm{vm}}=3$ and $\varepsilon_{\mathrm{vm}}=21$ followed by flash annealing. Microstructures are analyzed by optical microscopy, scanning electron microscopy and transmission electron microscopy. Mechanical properties are evaluated by hardness testing. Yield strength of materials is calculated from hardness values. Flash annealing (at $675^{\circ} \mathrm{C}$ ) of ECAPed samples for $\varepsilon_{\mathrm{vm}}=3$ and $\varepsilon_{\mathrm{vm}}=21$ results in abnormal subgrain growth and abnormal grain growth, respectively. Flash annealing at $700{ }^{\circ} \mathrm{C}$ of ECAPed $\left(\right.$ at $\left.\varepsilon_{\mathrm{vm}}=3\right)$ IF steel converts abnormally grown subgrains to grains which serve as nuclei for recrystallization and that result in bimodal grain size distribution. Bimodal grain size distribution is also produced when ECAPed IF steel for $\varepsilon_{\mathrm{vm}}=21$ is flash annealed at $675^{\circ} \mathrm{C}$ due to abnormal grain growth or secondary recrystallization. Flash annealing of IF steel samples ECAPed for low $\varepsilon_{\mathrm{vm}}$, in the temperature range $600-675{ }^{\circ} \mathrm{C}$, decreases the hardness continuously with increase in the annealing temperature but it increases at high $\varepsilon_{\mathrm{vm}}$. The former is due to annihilation of defects but the later is caused by ordering of nonequilibrium boundaries. The hardening and strengthening behaviors are similar.
\end{abstract}

Keywords ECAP, flash annealing, interstitial-free steel, scanning electron microscopy, transmission electron microscopy

\section{Introduction}

Interstitial-free (IF) steel is one of the recently developed steels used widely in the automotive industry because of its excellent deep drawability and high planar isotropy when the microstructure contains micrometer size grains (Ref 1) but it possesses low strength (Ref 2, 3). The strength can be improved by various strengthening methods. Most of the strengthening mechanisms lower ductility and formability. The grain size refinement is the only mechanism that improves strength with retained or improved ductility (Ref 4-6). Grain size can be reduced to ultrafine grain (UFG) range by severe plastic deformation (SPD) techniques (Ref 4, 5, 7-10). UFG steel is several times stronger than its coarse-grained counterpart, but it suffers with low ductility due to restricted dislocation activities in submicron size grained alloys (Ref 4-6). The SPD methods can produce UFGs by imposition of extremely large plastic strain to the material while preserving the initial dimensions of the workpiece (Ref 5, 7, 11, 12). Among the SPD techniques, the ECAP seems to be the most viable method because of the fact that bulk material can be deformed without any change in

Deepa Verma, Shobhit A. Pandey, Anushka Bansal, Shwetank Upadhyay, N.K. Mukhopadhyay, G.V.S. Sastry, and R. Manna, Department of Metallurgical Engineering, Indian Institute of Technology (Banaras Hindu University), Varanasi, Uttar Pradesh 221 005, India. Contact e-mails: rmanna.met@iitbhu.ac.in and rpmanna@rediffmail.com. cross section of the workpiece and in reasonable dimension limited by the capacity of press (Ref $8,13-15)$. This technique has been applied to synthesize bulk UFG structure in IF steel sheets (Ref 2, 3, 16-21) with excellent mechanical properties (Ref 16-22). However, the UFG microstructure brought about limited ductility with a few percent uniform elongation that limits its applications (Ref 23). Previous reports have shown that the ductility of UFG materials can be enhanced without compromising the strength by appropriate annealing treatments after SPD (Ref 22-25). This improvement was attributed to the bimodal grain size distribution introduced into the deformed microstructure with the combination of fine and coarse grains (Ref 25-29). Review of UFG low carbon steel suggests that both high strength and ductility can be achieved by combining a few percentage of micron-sized $(1-10 \mu \mathrm{m})$ grains in UFG matrix (Ref 4). In addition, the annealing synthesized can be applied also to the UFG materials processed by the SPD techniques to obtain a microstructure with enhanced stability (Ref 15). Wang et al. (Ref 26) annealed nano-grained $\mathrm{Cu}$ which resulted in a bimodal grain size distribution, with $\sim 25 \%$ volume fraction of micrometer-sized grains of $1-3 \mu \mathrm{m}$ embedded inside a matrix of $\sim 75 \%$ volume fraction of nanocrystalline and ultrafine grains $(<300 \mathrm{~nm})$. Bimodal grain size distribution is reported in IF steel ECAPed for equivalent strain $\left(\varepsilon_{\mathrm{vm}}\right) 9.24$ followed by annealing at $500{ }^{\circ} \mathrm{C}$ for $1 \mathrm{~h}$ duration due to recrystallization and coarsening of grains (Ref 2). UFG material containing ferrite and cementite microstructure with bimodal distribution of ferrite grains is reported to have a larger impact toughness compared to the material containing ferrite and pearlite, quenched and quenched and tempered martensite, in a low carbon steel (Ref 30). In case of commercial purity UFG Al, considerable efforts to introduce a bimodal grain structure failed (Ref 31 ), since grain coarsening occurred in a more or less homogeneous manner. The reason for this is reported as strong and rapid initial recovery and no left driving 


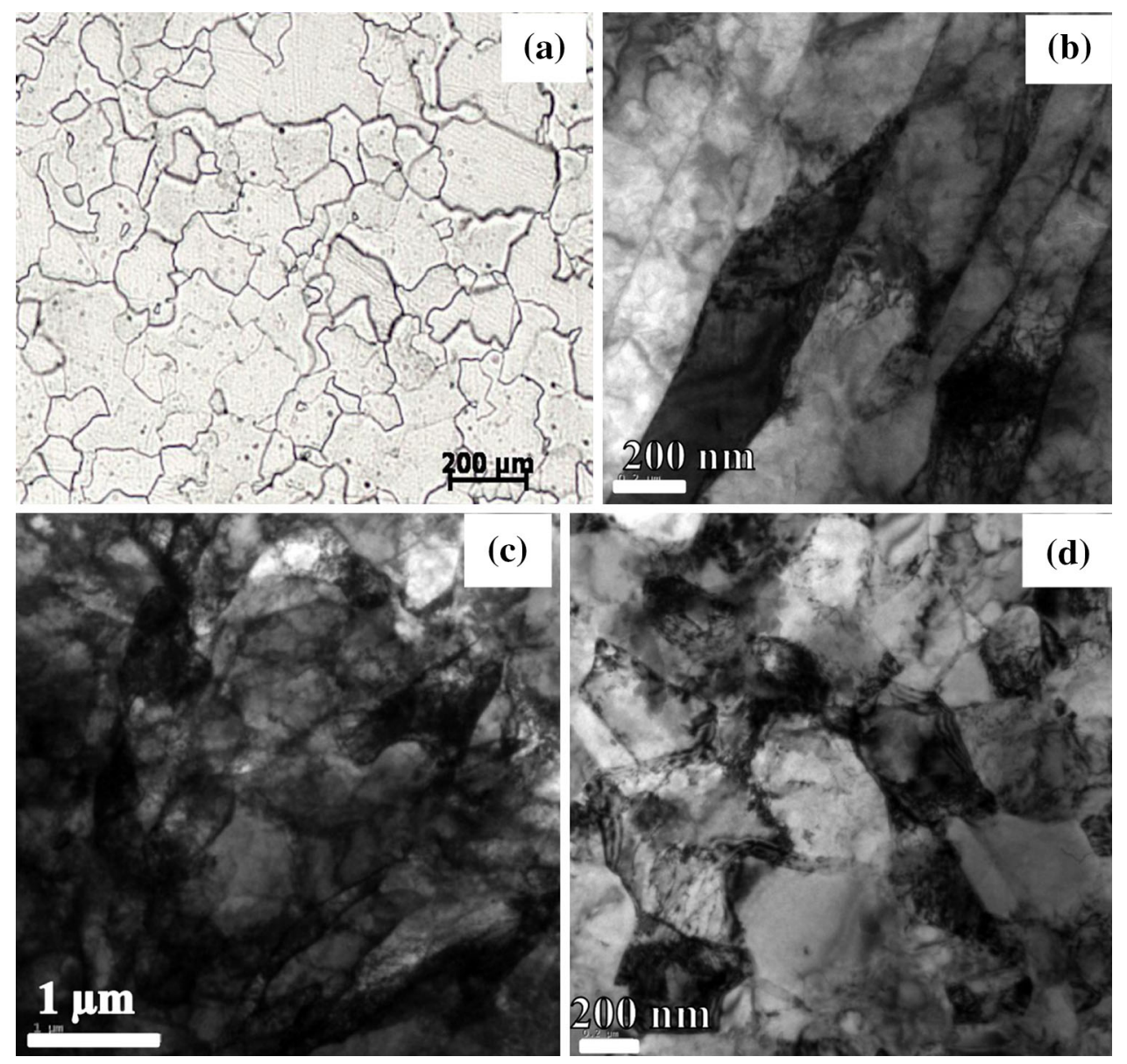

Fig. 1 (a) Optical microstructure of as-received IF steel; TEM bright field images of ECAP3 (b-c) and ECAP21 (d)

force for subsequent recrystallization, favoured by high stacking fault energy. Although some reports are available on the processing of UFG IF steel synthesized by ECAP (Ref 2, 1619) followed by prolonged isothermal annealing treatments (Ref 16, 32), however, to the best of our knowledge, no systematic study has been published yet on the effect of flash annealing of UFG IF steel to get bimodal grain size distribution. Therefore, the present work is aimed at developing the microstructure with bimodal/multimodal grain size distribution in IF steel by ECAP followed by flash annealing.

\section{Experimental Details}

The workpieces of $15 \mathrm{~mm}$ diameter and $60 \mathrm{~mm}$ length are prepared from the hot-rolled plate of IF steel. The chemical composition of steel sample used for this study is C- $0.0038 \%$, $\mathrm{Mn}-0.5 \%$, Si-0.008\%, S-0.007, P-0.036, Ti-0.057, Nb-0.016\%, Al- $0.031 \%$ (all by wt.\%) and balance is Fe. The workpieces are deformed at room temperature by the ECAP adopting the route $\mathrm{Bc}$ in which the sample is rotated by $90^{\circ}$ about its axis always in one direction between two passes to obtain homogeneity in deformation (Ref 8 ) using a hydraulic universal testing machine of 30 ton capacity. The workpieces are coated with a lubricant mixture of high-density paraffin with $\mathrm{MoS}_{2}$ to reduce the friction between the workpiece and the die. The ECAP die is consisted of two channels of $15 \mathrm{~mm}$ diameter intersecting at an inner angle $(\Phi) 120^{\circ}$ and an outer arc angle $(\Psi) 60^{\circ}$ that introduces an equivalent strain of $\sim 0.6$ in every passage of the workpiece through the die. The workpieces are deformed to equivalent strains $\left(\varepsilon_{\mathrm{vm}}\right)$ levels of 3 and 21 , and the deformed samples are designated as ECAP3 and ECAP21, respectively. The deformed samples are sectioned along $\mathrm{Y}$ plane for microstructural investigation. The $\mathrm{X}$ plane is the transverse plane perpendicular to the extrusion direction. The $\mathrm{Y}$ plane is the flow plane vertical to the extruded workpiece, and $\mathrm{Z}$ plane is the horizontal plane but parallel to the top surface along the extrusion direction (Ref 8). The ECAPed samples are flash annealed for $5 \mathrm{~min}$ in the $100 \% \mathrm{NaNO}_{3}$ melt maintained at $550-700{ }^{\circ} \mathrm{C}$ and in the air furnace at $725-750{ }^{\circ} \mathrm{C}$ followed by water quenching. The flash-annealed ECAP3 or ECAP21 samples are designated as ECAP3-FAT or ECAP21-FAT, respectively, where $\mathrm{T}$ indicates the temperature of annealing. The grain size of the as-received material is measured from the optical micrograph using Heyn's lineal intercept method. Thin foils of $3 \mathrm{~mm}$ diameter and $40 \mu \mathrm{m}$ thickness are electropolished at $-30{ }^{\circ} \mathrm{C}$ using an electrolyte of 5 vol. \% perchloric acid and 95 vol. $\%$ methanol at $30 \mathrm{~V}, \sim 60 \mathrm{~mA}$. The detailed microstructures are characterized by Tecnai $20 \mathrm{G}^{2}$ transmission electron microscope (TEM) operating at $200 \mathrm{kV}$. The annealed samples of $10 \times 10 \mathrm{~mm}^{2}$ are metallographically polished followed by electropolishing at $10{ }^{\circ} \mathrm{C}, 16 \mathrm{~V}$ for $40 \mathrm{~s}$ using 20 vol.\% perchloric acid and 80 vol.\% methanol. The electropolished samples are investigated in Quanta 200 FEG scanning electron microscope (SEM). The hardness is mea- 

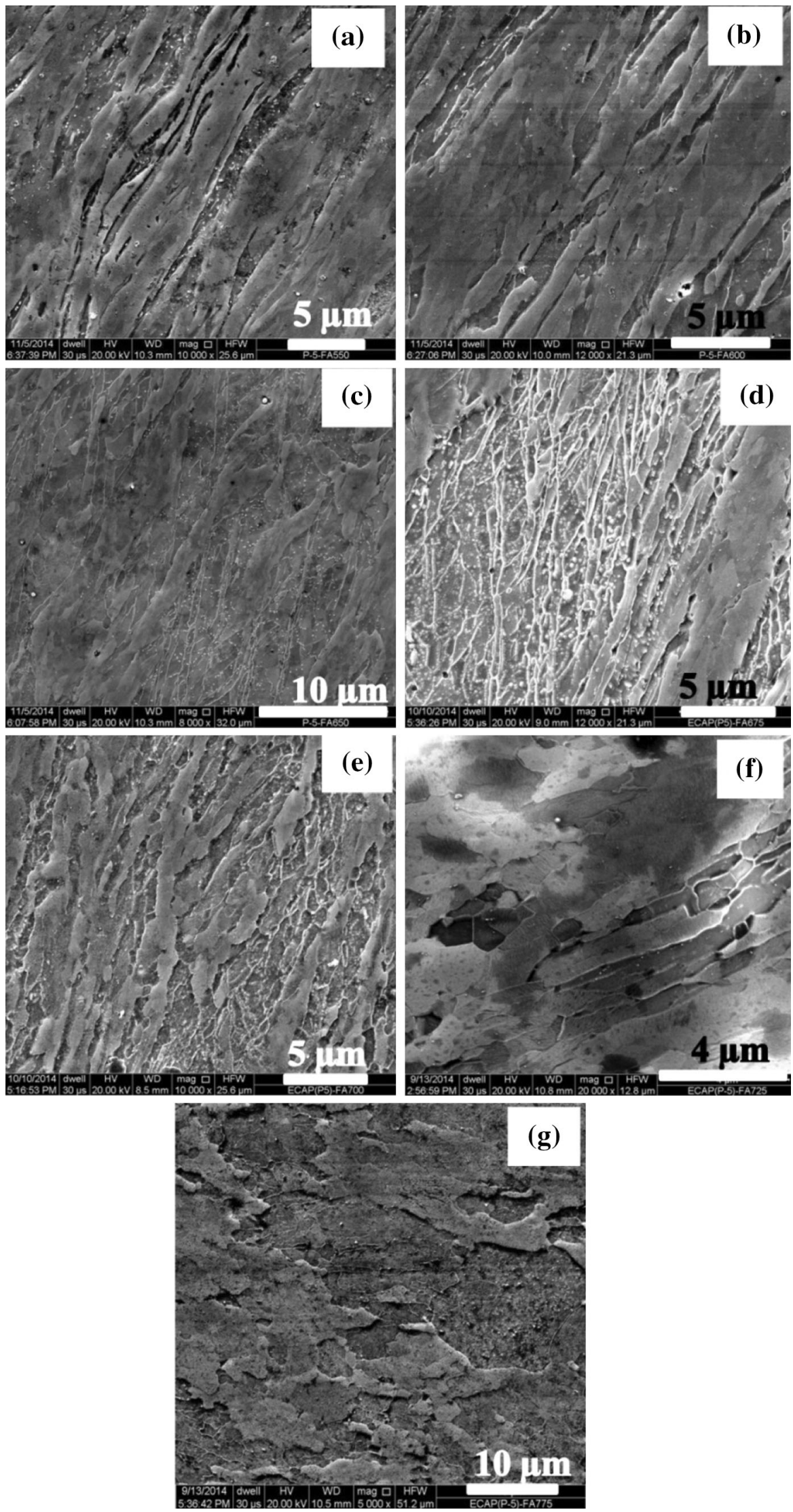

Fig. 2 SEM images of IF steel deformed up to $\varepsilon_{\mathrm{vm}}=3$ and flash-annealed (a) ECAP3-FA550, (b) ECAP3-FA600, (c) ECAP3-FA650, (d) ECAP3-FA675, (e) ECAP3-FA700, (f) ECAP3-FA725 and (g) ECAP3-FA750 

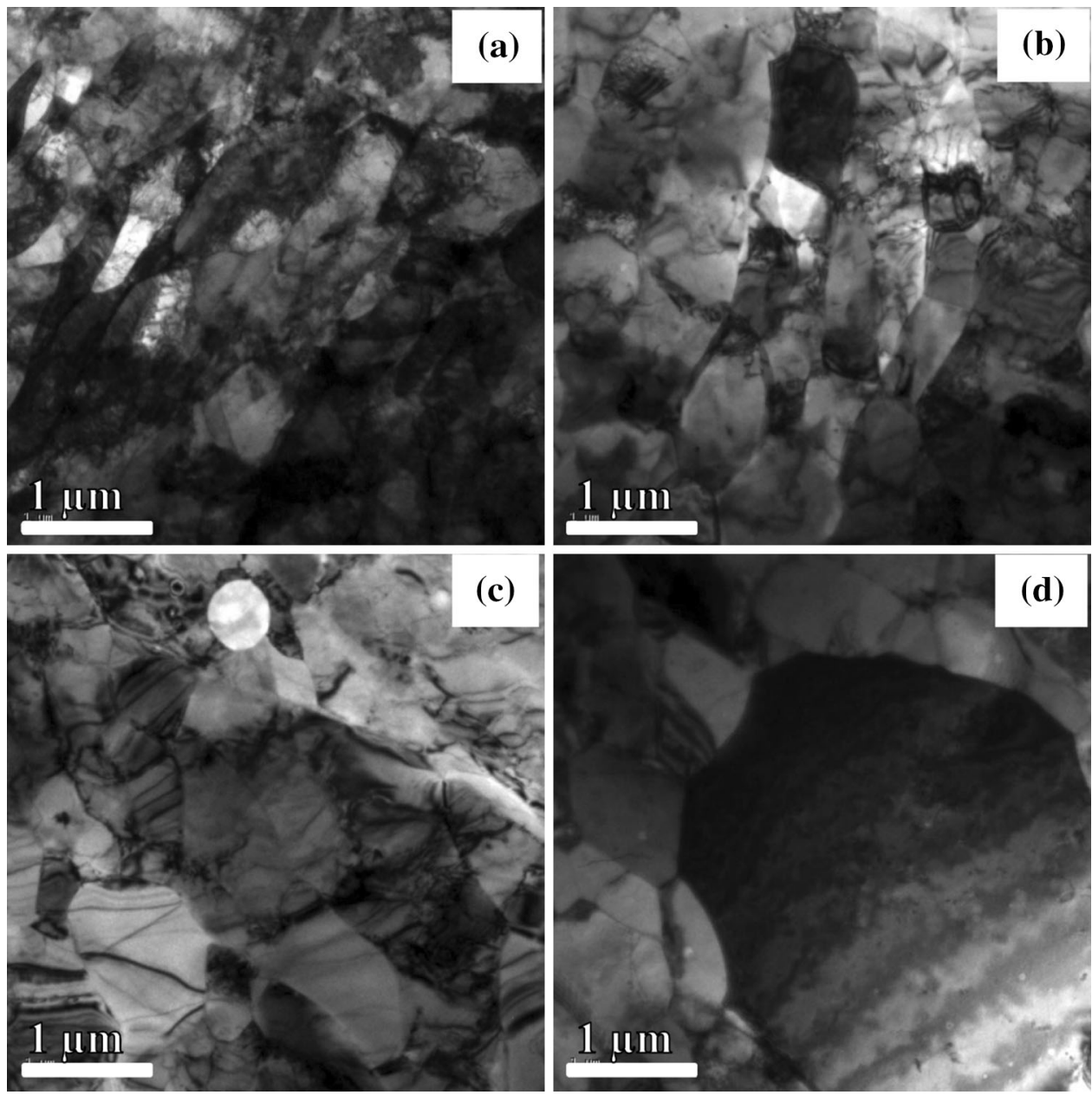

Fig. 3 TEM bright field images of IF steel deformed up to $\varepsilon_{\mathrm{vm}}=3$ and flash-annealed (a) ECAP3-FA675, (b) ECAP3-FA700, (c) ECAP3FA725 and (d) ECAP3-FA750

sured by Shimadzu HMV-2T microhardness tester at $980 \mathrm{mN}$ load using Vickers indenter in the extrusion plane, i.e., the $\mathrm{Y}$ plane of ECAPed samples. The theoritical hardness values are calculated from Hall-Petch constants (Ho and K, calculated from a fit by method of least square from experimental hardness values) within the grain size range. From the measured hardness value and tensile test data reported elsewhere (Ref $33,34)$, ratio of hardness to yield strength is calculated in two regions - one in deformed state and other well-annealed state. From these ratios, yield strength is calculated for both the regions in the present experimental conditions for different flash-annealed IF steels from the theoretical harness values.

\section{Results and Discussion}

Figure 1(a) represents an optical micrograph of the asreceived IF steel showing the microstructure of mostly equiaxed coarse-grained structure of ferrite with an average grain size of about $57.6 \pm 21 \mu \mathrm{m}$. At $\varepsilon_{\mathrm{vm}}=3$, in ECAP3, coarse grains get split into deformation bands of width $298 \pm 30 \mathrm{~nm}$ and bands get aligned toward deformation direction, which can be observed in Fig. 1(b). Some of the bands are also fragmented due to the orthogonal change in deformation direction between two passes (Fig. 1b). Some of the dislocations get dynamically recovered during deformation and get distributed unevenly as well as tangled to form subgrain boundaries (Fig. 1c). At $\varepsilon_{\mathrm{vm}}=21$ (in ECAP21), Fig. 1(d) shows that the near-equiaxed ultrafine-grained structure which is developed progressively by shearing of ribbon grains and average grain size reaches $256 \pm 61 \mathrm{~nm}$. At low strain level, low fraction of high-angle grain boundaries exists but with increase in strain low-angle grain boundaries are being converted to the boundary of higher misorientation by progressive lattice rotation. However, a few grains still contain significant amount of dislocations. Boundaries of grains are showing some contour type structures which are indicative of their highly strained (nonequilibrium) condition (Fig. 1d).

The microstructure of ECAP3-FA550 consists of recovered banded structure of average bandwidth of $444 \pm 54 \mathrm{~nm}$ (Fig. 2a). Annealing of ECAP3 at $600{ }^{\circ} \mathrm{C}$, i.e., the ECAP3FA600 sample also shows the elongated grains with the recovered banded structures of size $448 \pm 35 \mathrm{~nm}$ (Fig. 2b). When ECAP3 sample is flash annealed at $650{ }^{\circ} \mathrm{C}$, the morphology of grains is maintained (Fig. 2c) and the bands grow to $459 \pm 87 \mathrm{~nm}$ by grain boundary migration. Subgrain growth is dependent on energy of low-angle grain boundaries, and growth rate is a function of subgrain misorientation (Ref 35 ). When the deformed samples are annealed at $675^{\circ} \mathrm{C}$, the 

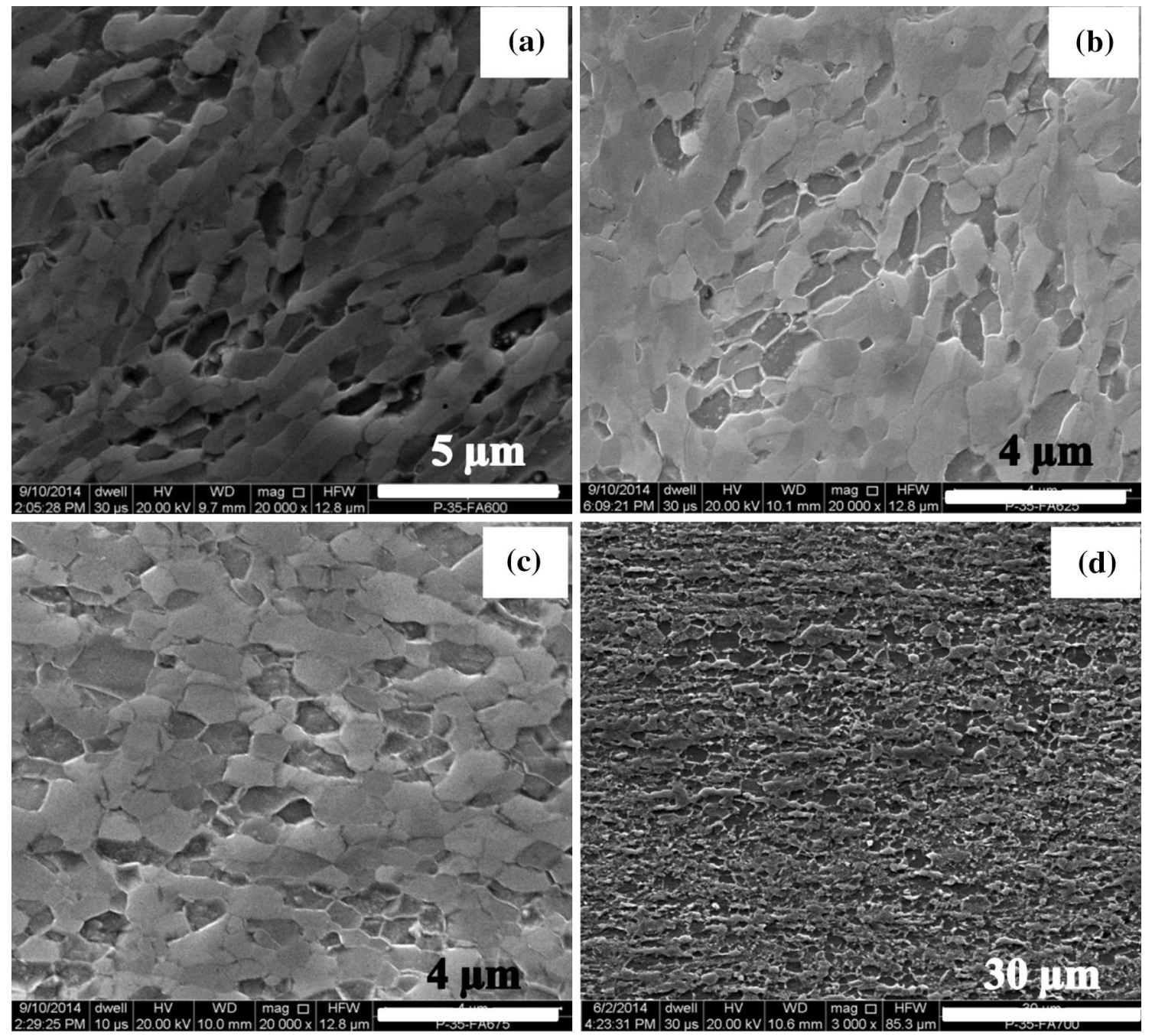

Fig. 4 SEM images of IF steel deformed up to $\varepsilon_{\mathrm{vm}}=21$ and flash-annealed (a) ECAP21-FA600, (b) ECAP21-FA625, (c) ECAP21-FA675 and (d) ECAP21-FA700

discontinuous subgrain growth occurs. The microstructure contains the fine subgrains of $319 \pm 73 \mathrm{~nm}$ size along with coarse subgrains of $838 \pm 20 \mathrm{~nm}$ (Fig. 2d, 3a). Further increasing annealing temperature to $700{ }^{\circ} \mathrm{C}$, some of the abnormally grown subgrains eventually become grains and that leads to recrystallization. The recrystallized microstructure shows bimodal grain size distribution where equiaxed fine grains coexist with abnormally grown grains (Fig. 2e, $3 b)$. The microstructure contains $77 \%$ fine grains of average size of $620 \pm 28 \mathrm{~nm}$ and $23 \%$ of coarse grains of average size of $1.5 \pm 0.24 \mu \mathrm{m}$ (Fig. 2e, 3b; Table 1). On annealing of ECAP3 at $725^{\circ} \mathrm{C}$, grains are uniformly coarsened to $1.7 \pm 0.38 \mu \mathrm{m}$ (Fig. 2f, 3c). Flash annealing at $750{ }^{\circ} \mathrm{C}$ results in coarsening of grains to average size of $2.6 \pm 0.36 \mu \mathrm{m}$ (Fig. 2g, 3d).

On flash annealing of ECAP2 1 sample at $600{ }^{\circ} \mathrm{C}$, fine grains increase to average size of $377 \pm 94 \mathrm{~nm}$ (Fig. 4a, 5a) but the elongated nature is maintained. When ECAP21 sample is annealed at $625{ }^{\circ} \mathrm{C}$, recrystallization begins and microstructure contains $93 \%$ fine grains of average size $388 \pm 83 \mathrm{~nm}$ with $7 \%$ coarse grains of average size of $1.2 \pm 0.26 \mu \mathrm{m}$ (Fig. 4b, 5b; Table 1). On flash annealing at $675^{\circ} \mathrm{C}$, the material is recrystallized and that results in bimodal grain size distribution.
The microstructure contains $81.5 \%$ recrystallized grains of average size of $455 \pm 60 \mathrm{~nm}$ and $18.5 \%$ of abnormally grown grains of $1.3 \pm 0.21 \mu \mathrm{m}$ (Fig. $4 \mathrm{c}, 5 \mathrm{c}$ ). Further flash annealing at $700{ }^{\circ} \mathrm{C}$ leads to uniform coarsening of grains to $3.8 \pm 0.39 \mu \mathrm{m}$ size (Fig. 4d, 5d). Figure 6(a) represents the variation of Vickers microhardness of ECAP3 with the annealing temperature. As deformed ECAP3 sample shows the highest hardness value of $323 \mathrm{VHN}$. As this material is annealed, hardness remains at $360 \mathrm{VHN}$ due to the recovery and slightly decreases to $342 \mathrm{VHN}$ at $650{ }^{\circ} \mathrm{C}$. Recovery observed after flash annealing at $550,600,650{ }^{\circ} \mathrm{C}$ of ECAP3 is referred to rearrangement of dislocations and formation of cell structures (as observed in Fig. 2a-c, 4a) as morphology of microstructure is not changed and most of the grains are of elongated in nature. At $675^{\circ} \mathrm{C}$, hardness value decreases to $302 \mathrm{VHN}$ due to abnormal grain growth. The rate of decrease in the hardness is rapid up to $700{ }^{\circ} \mathrm{C}$ due to recrystallization and consequently the hardness value drops down to $243 \mathrm{VHN}$. The discontinuous subgrain growth is because of high-angle boundary mobility for small misorientations. Those subgrains which are slightly more misoriented than the average give rise to discontinuous subgrain growth. During plastic deformation at $\varepsilon_{\mathrm{vm}}=3$, high density of dislocations gets annihilated and forms subgrain and 

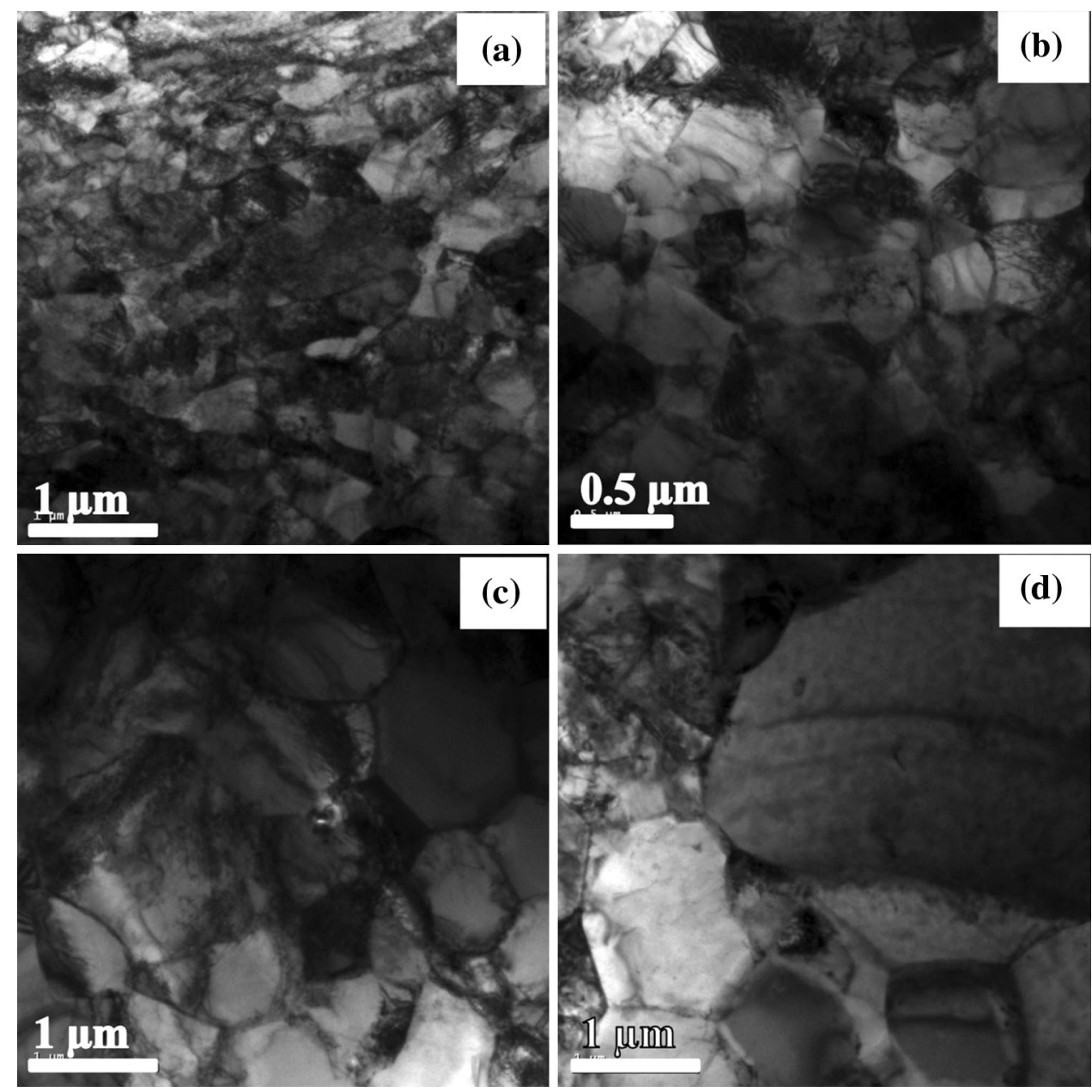

Fig. 5 TEM images of IF steel deformed up to $\varepsilon_{\mathrm{vm}}=21$ and flash-annealed (a) ECAP21-FA600, (b) ECAP21-FA625, (c) ECAP21-FA675 and (d) ECAP21-FA700
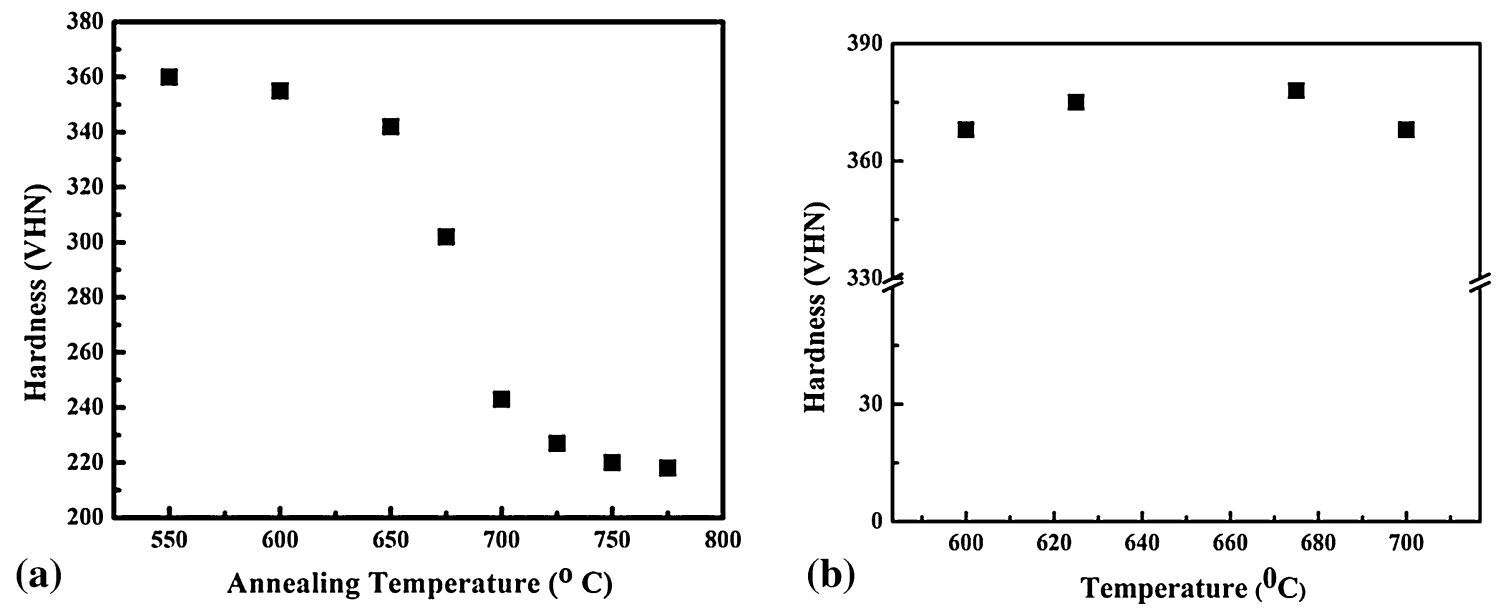

Fig. 6 Variation of hardness value with flash annealing temperature of deformed IF steel at (a) $\varepsilon_{\mathrm{vm}}=3$ and (b) $\varepsilon_{\mathrm{vm}}=21$ )

cell structures. When this material is annealed, a few subgrains grow abnormally large due to nonuniform grain boundary mobility. These subgrains transform to grains and serve as nuclei for recrystallization (Ref 36). Hardness drops significantly at this stage due to rearrangement and annihilation of dislocations. The process of abnormal subgrain growth is truncated by onset of recrystallization (Ref 35) which is observed after flash annealing at $700{ }^{\circ} \mathrm{C}$ (Fig. 3b) and that results in rapid decrease in hardness (Fig. 6a). Recrystallized grains are seen to nucleate at the periphery of abnormally grown grains (Fig. 3b) where abnormally grown subgrain boundary acts as nuclei for recrystallization to occur. Nucle- 

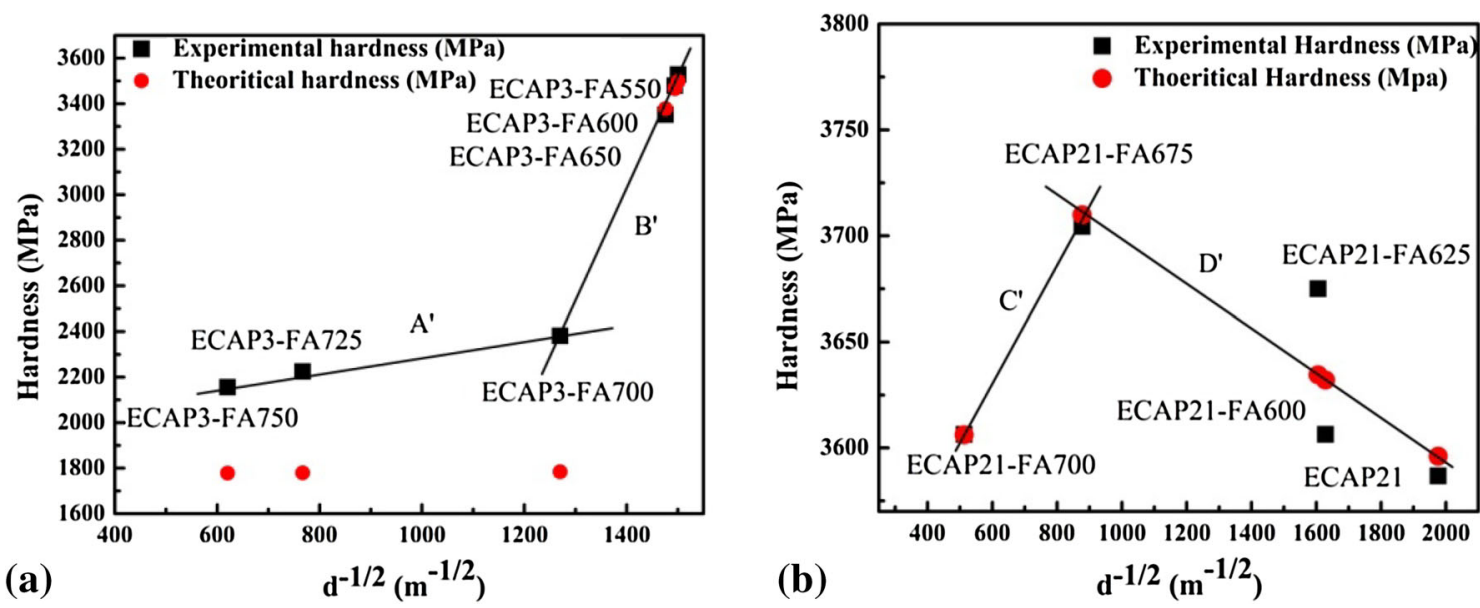

Fig. 7 Variation of hardness with inverse of grain size $\left(d^{-1 / 2}\right)$ for flash-annealed ECAPed IF steel samples ECAPed for (a) $\varepsilon_{\mathrm{vm}}=3$ and (b) $\varepsilon_{\mathrm{vm}}=21$. Theoritical hardness values are calculated based on constants and grain size values which are indicated as red color filled circles in respective graphs
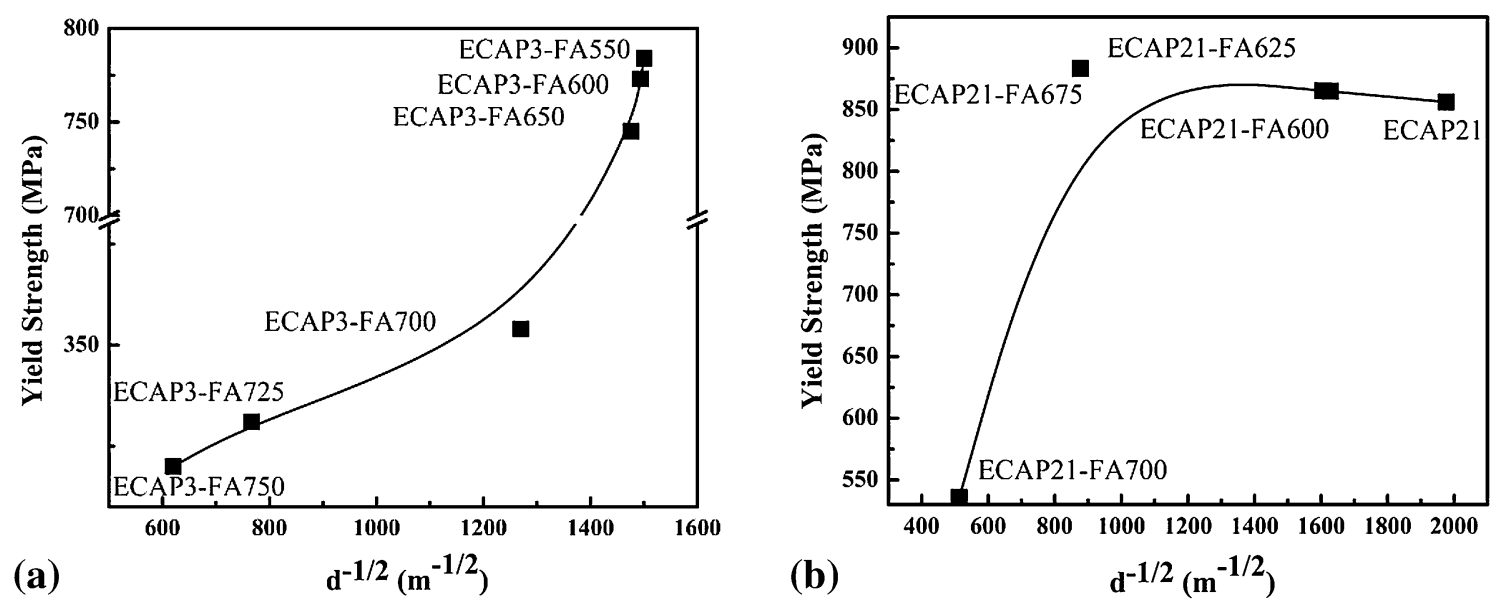

Fig. 8 Variation of calculated yield strength with grain size ${ }^{-1 / 2}$ for (a) ECAP 3 category and (b) ECAP21 category IF steel samples

ation of recrystallized grains was predicted through modeling by number of workers (Ref $35,37,38)$.

Further annealing of ECAP3 at $725^{\circ} \mathrm{C}$ leads to decrease in hardness to $227 \mathrm{VHN}$ due to coarsening of fine grains (Fig. 2f, 4d). Coarse grains grow through grain boundary migration by consuming smaller grains as coarse grains have lower relative grain boundary curvature (Ref 39, 40). Even though grain growth is observed at this temperature but effect of deformation is visible as dislocations as well as cells are present (Fig. 3c). Annealing at $750{ }^{\circ} \mathrm{C}$ brings uniform coarsening (Fig. 2f, 3d) with sharp grain boundaries. Hardness at this temperature range decreases and becomes minimum (Fig. 6a).

On flash annealing of ECAP2 1 at $600{ }^{\circ} \mathrm{C}$, the recovery is observed with increased subgrain size that leaves the hardness value constant similar to that of deformed state. After the flash annealing of ECAP21 sample at 625 and $675{ }^{\circ} \mathrm{C}$, the increase in hardness could be observed even though the grain size is more in the later case (Fig. 4b, c, 5b, c).

The relation between microhardness $(H)$ and grain size $(d)$ can be presented by classical Hall-Petch (H-P) equation (Ref $41,42)$ as

$$
H=H_{0}+k d^{-1 / 2}
$$

where $H_{0}$ is the hardness of coarse-grained material and $K$ is gradient which is constant for material of single-phase micron-sized polycrystalline grains.

Figure 7(a) represents variation in hardness with inverse square root of grain size for IF steel samples ECAPed for $\varepsilon_{\mathrm{vm}}=3$ followed by flash annealing at $550-750{ }^{\circ} \mathrm{C}$. A linear fit of method of least square from the experimental hardness values $(\mathrm{MPa})$ against the inverse square root of the grain size $\left(d^{-1 / 2}\right)$ results in a value of $H_{0}$ and $\mathrm{K}$ are $-7160.3 \mathrm{MPa}$ and $7.12 \mathrm{MPa} \mathrm{m}^{1 / 2}$, respectively, for samples annealed at 550 to $650{ }^{\circ} \mathrm{C}$ (line $\mathrm{B}^{\prime}$ ) and $1954 \mathrm{MPa}$ and $0.34 \mathrm{MPa} \mathrm{m}^{1 / 2}$, respectively, for samples annealed at $700-750{ }^{\circ} \mathrm{C}$ (line $\mathrm{A}^{\prime}$ ). The equations which were formed by least square method are $H=1954 \mathrm{MPa}+0.34 \mathrm{MPam} 1 / 2 d^{-1 / 2}$ (for $\mathrm{A}^{\prime}$ ) and $\mathrm{H}=-7160.3 \mathrm{MPa}+7.12 \mathrm{MPa} \mathrm{m}^{1 / 2} d^{-1 / 2}$ (for line $\mathrm{B}^{\prime}$ ). This indicates the mechanism of strengthening changes at $700{ }^{\circ} \mathrm{C}$. At lower temperature, abnormal subgrain growth but above $700{ }^{\circ} \mathrm{C}$ it changes to recrystallization and normal grain growth. Whereas, fit of the experimental hardness values against the 
inverse square root of the grain size gives negative slope and Hall-Petch constants $H_{\mathrm{o}}$ and $K$ are $3801 \mathrm{MPa}$ and $-0.104 \mathrm{MPa} \mathrm{m}^{1 / 2}$, respectively, in case of flash-annealed ECAP21 at $600-675{ }^{\circ} \mathrm{C}$ (line D') (Fig. 7b). Hardness increases due to ordering of nonequilibrium boundaries which approaches toward equilibrium but it decreases when flash annealed at $700{ }^{\circ} \mathrm{C}$ due to coarsening of grains where HallPetch constants $\mathrm{Ho}$ and $\mathrm{K}$ become $3468 \mathrm{MPa}$ and $0.26 \mathrm{MPa} \mathrm{m}^{1 / 2}$, respectively, (line $\mathrm{C}^{\prime}$ ).

Due to limited amount of processed material, the bulk mechanical property like tensile testing could not be performed on all materials. From the measured hardness value and tensile test data reported elsewhere (Ref 33, 34), ratio of hardness to yield strength is calculated in two regions - one in deformed state and other well-annealed state. From these ratios, yield strength is calculated using measured hardness values for different flash-annealed IF steel [43]. The calculated yield strength values (Table 1) are plotted against grain size $^{-1 / 2}$ (Fig. 8a, b). Hardening and strengthening behaviors are similar for each type of ECAPed and flash-annealed IF steel samples.

Increase in strength after annealing is observed by many authors (Ref 44-48). Hasnaoui et al. (Ref 44) have suggested by molecular dynamic simulation that after processing, grain boundaries of nano-crystalline materials are often in a nonequilibrium state, and annealing results in grain boundaries and triple-junction regions to approach toward equilibrium which strengthens the material. Greer et al. have proposed that in small crystals, the dislocations travel smaller distance to free surface, thereby reducing the probability of dislocation multiplication processes ( $\operatorname{Ref} 46$ ). As a consequence dislocations leave the small crystals before getting multiplied and dislocation starvation region is created. After dislocation starvation conditions very high stresses are required to nucleate new dislocation and lead to increased strength (Ref 46). Hung et al. have suggested that closely spaced high-angle boundaries act as dislocation sinks to reduce the number of dislocation sources during annealing and lead to increase in the yield stress to activate new dislocation sources during straining (Ref 47). Further rising flash annealing temperature for ECAP21 to $700{ }^{\circ} \mathrm{C}$, the grain size increases to a large value (Fig. 4d, 6b) leading to lowering of hardness.

\section{Conclusions}

The following conclusions can be drawn from the present investigation:

1. Equal-channel angular pressing of IF steel followed by flash annealing can be utilized to produce bimodal grain size distribution in the ultrafine grain range even though the mechanism of bimodal grain size distribution differs for different equivalent strains. Flash annealing (at $675^{\circ} \mathrm{C}$ ) of IF steel samples ECAPed for $\varepsilon_{\mathrm{vm}}=3$ and $\varepsilon_{\mathrm{vm}}=21$ results in abnormal subgrain growth and abnormal grain growth/secondary recrystallization. Flash annealing of lower equivalent strained sample at $700{ }^{\circ} \mathrm{C}$ converts abnormally grown subgrains to grain which serve as nuclei for recrystallization.

2. The recrystallization temperature of ultrafine-grained IF steel decreases with the increase in equivalent strain. 
3. The temperature of the abnormal grain growth in IF steel increases with decrease in equivalent strain.

4. The hardness of severely deformed IF steel can be retained by flash annealing up to $650{ }^{\circ} \mathrm{C}$ for short duration of $300 \mathrm{~s}$.

5. Flash annealing of IF steel samples ECAPed for high $\varepsilon_{\mathrm{vm}}$, in the temperature range $600-675{ }^{\circ} \mathrm{C}$, increases the hardness continuously with increase in the annealing temperature due to ordering of nonequilibrium boundaries toward equilibrium.

6. Hardening and strengthening behavior are similar for ECAPed IF steel.

\section{Acknowledgments}

Authors wish to thank the Department of Science and Technology (DST), Government of India for financial support under the Project No. SR/S3/ME/009/2010 (G) dated July 14, 2011.

\section{Open Access}

This article is distributed under the terms of the Creative Commons Attribution 4.0 International License (http://creativecommons.org/ licenses/by/4.0/), which permits unrestricted use, distribution, and reproduction in any medium, provided you give appropriate credit to the original author(s) and the source, provide a link to the Creative Commons license, and indicate if changes were made.

\section{References}

1. S.-H. Lee, H. Utsunomiya, and T. Sakai, Microstructures and Mechanical Properties of Ultra Low Carbon Interstitial Free Steel Severely Deformed by a Multi-stack Accumulative Roll Bonding Process, Metall. Mater. Trans. A, 2004, 45A, p 2177-2181

2. T. Niendorf, D. Canadinc, H.J. Maier, and I. Karaman, The Role of Heat Treatment on the Cyclic Stress-Strain Response of UltrafineGrained Interstitial-Free Steel, Int. J. Fatigue, 2008, 30, p 426-436

3. G. Purcek, O. Saray, M.I. Nagimov, A.A. Nazarov, I.M. Safarov, V.N. Danilenko, O.R. Valiakhmetov, and R.R. Mulyukov, Microstructure and Mechanical Behavior of UFG Copper Processed by ECAP Following Different Processing Regimes, Phil. Mag., 2012, 92(6), p 690-704

4. R. Song, D. Ponge, D. Raabe, J.G. Speer, and D.K. Matlock, Overview of Processing, Microstructure and Mechanical Properties of Ultrafine Grained bcc Steels, Mater. Sci. Eng. A, 2006, 441, p 1-17

5. R.Z. Valiev, R.K. Islamgaliev, and I.V. Alexandrov, Bulk Nanostructured Materials from Severe Plastic Deformation, Prog. Mater Sci. 2000, 45, p 103-189

6. Y. Estrin and A. Vinogradov, Extreme Grain Refinement by Severe Plastic Deformation: A Wealth of Challenging Science, Acta Mater. 2013, 61, p 782-817

7. A.P. Zhilyaev and T.G. Langdon, Using High-Pressure Torsion for Metal Processing: Fundamentals and Applications, Prog. Mater Sci., 2008, 53, p 893-979

8. R.Z. Valiev and T.G. Langdon, Principles of Equal-Channel Angular Pressing as a Processing Tool for Grain Refinement, Prog. Mater Sci., 2006, 51, p 881-981

9. A.P. Zhilyaev, S. Lee, G.V. Nurislamova, R.Z. Valiev, and T.G. Langdon, Microhardness and Microstructural Evolution in Pure Nickel During High-Pressure Torsion, Scr. Mater., 2001, 44, p 2753-2758

10. S.H. Lee, T. Sakai, Y. Saito, H. Utsunomiya, and N. Tsuji, Strengthening of Sheath-Rolled Aluminum Based MMC by the ARB Process, Mater. Trans. JIM, 1999, 40, p 1422-1428
11. R.Z. Valiev, I.V. Alexandrov, Y.T. Zhu, and T.C. Lowe, Paradox of Strength and Ductility in Metals Processed Bysevere Plastic Deformation, J. Mater. Res., 2002, 17(1), p 5-8

12. Y. Saito, H. Utsunomiya, N. Tsuji, and T. Sakai, Novel Ultra-High Straining Process for Bulk Materials-Development of the Accumulative Roll-Bonding (ARB) Process, Acta Mater., 1999, 47, p 579-583

13. X. Zhang, H. Wang, and C.C. Koch, Mechanical Behavior of Bulk Ultrafine-Grained and Nanocrystalline Zn, Rev. Adv. Mater. Sci., 2004, 6, p 53-93

14. G.J. Raab, R.Z. Valiev, T.C. Lowe, and Y.T. Zhu, Continuous Processing of Ultrafine Grained Al by ECAP-Conform, Mater. Sci. Eng. A, 2004, 382, p 30-34

15. H.-S. Kim, P. Quang, M.H. Seo, S.I. Hong, K.H. Baik, H.R. Lee, and D.M. Nghiep, Process Modelling of Equal Channel Angular Pressing for Ultrafine Grained Materials, Mater. Trans., 2004, 45(7), p 21722176

16. S.S. Hazra, E.V. Pereloma, and A.A. Gazder, Microstructure and Mechanical Properties after Annealing of Equal-Channel Angular Pressed Interstitial-Free Steel, Acta Mater., 2011, 59, p 4015-4029

17. T. Niendorf, D. Canadinc, H.J. Maier, and I. Karaman, On the Microstructural Stability of Ultrafine-Grained Interstitial-Free Steel Under Cyclic Loading, Metall. Mater. Trans. A, 2007, 38A, p 19461955

18. O. Saray, G. Purcek, and I. Karaman, Principles of Equal-Channel Angular Sheet Extrusion (ECASE): Application to IF-Steel Sheets, Rev. Adv. Mater. Sci., 2010, 25, p 42-51

19. H.S. Kim, W.S. Ryu, M. Janacek, S.C. Baik, and Y. Estrin, Effect of Equal Channel Angular Pressing on Microstructure and Mechanical Properties of IF Steel, Adv. Eng. Mater., 2005, 7, p 43-46

20. B. Yan, S. Dower, L. Jin, J. Shen, Y. Huang, and S. Jiao, Microstructure Evolution During Continuous Frictional Angular Extrusion of Interstitial-Free Steel, Mater. Sci. Forum, 2008, 584-586, p 631-636

21. Y.H. Jin and M.Y. Huh, Evolution of Textures and Microstructures in IF-Steel Sheets During Continuous Confined Strip Shearing and Subsequent Recrystallization Annealing, J. Mater. Sci., 2004, 39, p 5311-5314

22. N. Tsuji, S. Okuno, Y. Koizumi, and Y. Minamino, Toughness of Ultrafine Grained Ferritic Steels Fabricated by ARB and Annealing Process, Metall. Trans., 2004, 45(7), p 2272-2281

23. T.S. Wang, Z. Li, B. Zhang, X.J. Zhang, J.M. Deng, and F.C. Zhang, High Tensile Ductility and High Strength in Ultrafine-Grained LowCarbon Steel, Mater. Sci. Eng. A, 2010, 527, p 2798-2801

24. Y.-H. Zhao, X.-Z. Liao, S. Cheng, E. Ma, and Y.T. Zhu, Simultaneously Increasing the Ductility and Strength of Nanostructured Alloys, Adv. Mater., 2006, 18, p 2280-2283

25. N. Tsuji, N. Kamikawa, R. Ueji, N. Takata, H. Koyama, and D. Terada, Managing Both Strength and Ductility in Ultrafine Grained Steels, ISIJ Int., 2008, 48(8), p 1114-1121

26. Yinmin Wang, Mingwei Chen, Fenghua Zhou, and En Ma, Nature, 2002, 419, p 912-913

27. Y.M. Wang and E. Ma, Three Strategies to Achieve Uniform Tensile Deformation in a Nanostructured Metal, Acta Mater, 2004, 52, p 1699-1709

28. A.H. Shamdani, S. Khoddam, P.F. Thomson, and A. DehghanManshadi, Microstructure and Mechanical Properties of IF Steel Deformed During Plane Stress Local Torsion, J. Mater. Sci., 2012, 47(3), p 1582-1587

29. Y.-H. Zhao, T. Topping, J.F. Bingert, J.J. Thornton, A.M. Dangelewicz, Y. Li, W. Liu, Y. Zhu, Y. Zhou, and E.J. Lavernia, High Tensile Ductility and Strength in Bulk Nanostructured Nickel, Adv. Mater., 2008, 20, p 3028-3033

30. T. Hanamura, F. Yin, and K. Nagai, Ductile-Brittle Transition Temperature of Ultrafine Ferrite/Cementite Microstructure in a Low Carbon Steel Controlled by Effective Grain Size, ISIJ Int., 2004, 44(3), p 610-617

31. H. Mughrabi, H.W. Hoppel, and M. Kautz, Fatigue and Microstructure of Ultrafine-Grained Metals Produced by Severe Plastic Deformation, Scr. Mater., 2004, 51, p 807-812

32. G. Purcek, O. Saray, I. Karaman, and H.J. Maier, High Strength and High Ductility of Ultrafine-Grained, Interstitial-Free Steel Produced by ECAE and Annealing, Metal. Mater. Trans. A, 2012, 43(6), p 18841894

33. D. Verma, N.K. Mukhopadhyay, G.V.S. Sastry, and R. Manna, UltraHigh-Strength Interstitial-Free Steel Processed by Equal-Channel 
Angular Pressing At Large Equivalent Strain, Metall. Mater. Trans. A, 2016, 47, p 1803-1817

34. D. Verma, N.K. Mukhopadhyay, G.V.S. Sastry, R. Manna, Microstructure and Mechanical Properties of Ultrafine-Grained Interstitial-Free Steel Processed by ECAP. Trans. Indian. Inst. Met. (2016). doi: 10.1007/s12666-016-0881-0

35. F.J. Humphreys and M. Hatherly, Recrystallization and Related Annealing Phenomena, 2nd ed., Pergamon Press, Oxford, 1995, p 192-200

36. E.A. Holm, M.A. Miodownik, and A.D. Rollett, On Abnormal Subgrain Growth and the Origin of Recrystallization Nuclei, Acto Mater., 2003, 51, p 2701-2716

37. A.D. Rollett, E.A. Holm, T.R. McNelley (ed.), Recrystallization 96, TMS, Warrendale, PA, 1996, p 31-42

38. F.J. Humphreys, A Unified Theory of Recovery, Recrystallization and Grain Growth, Based on the Stability and Growth of Cellular Microstructures-I. The Basic Model, Acta Mater., 1997, 45, p 4231-4240

39. R.G. Cawthorn, Layered Intrusions, Elsevier, Amsterdam, 1996, p 91

40. C. Antonione, G. Della Gatta, G. Riontino, and G. Venturello, Grain Growth and Secondary Recrystallization in Iron, J. Mater. Sci., 1973, 8, p 1-10
41. E.O. Hall, The Deformation and Aging of Mild Steel: III. Discussion of Results, Proc. Phys. Soc. B, 1951, 64, p 747-753

42. N.J. Petch, The Cleavage Strength of Polycrystals, J. Iron Steel Inst., 1953, 174, p 25-28

43. P. Zhang, S.X. Li, and Z.F. Zhang, General Relationship Between Strength and Hardness, Mater. Sci. Eng. A, 2011, 529, p 62-73

44. A. Hasnaoui, H. Van Swygenhoven, and P.M. Derlet, On Nonequilibrium Grain Boundaries and Their Effect on Thermal and Mechanical Behaviour: A Molecular Dynamics Computer Simulation, Acta Mater, 2002, 50, p 3927-3939

45. A. Torrents, H. Yang, and F. Mohamed, Effect of Annealing on Hardness and the Modulus of Elasticity in Bulk Nanocrystalline Nickel, Metall. Mater. Trans. A, 2010, 41(3), p 621-630

46. J.R. Greer, W.C. Oliver, and W.D. Nix, Size Dependence of Mechanical Properties of Gold at the Micron Scale in the Absence of Strain Gradients, Acta Mater., 2005, 53, p 1821-1830

47. X. Huang, N. Hansen, and N. Tsuji, Hardening by Annealing and Softening by Deformation in Nanostructured Metals, Science, 2006, 312, p 249-251

48. N. Kamikawa, X. Huang, N. Tsuji, and N. Hansen, Strengthening Mechanisms in Nanostructured High-Purity Aluminium Deformed to High Strain and Annealed, Acta Mater., 2009, 57, p 4198-4208 